\title{
Transformações e atualidade da teoria crítica ${ }^{1}$
}

\section{Changes and actuality of the critical theory}

Vera Veiga França²

1 Uma primeira versão deste trabalho foi apresentada no I Simpósio de Crítica de Mídia: Como Criticam os que Criticam, realizado em 21 e 22 de setembro de 2017 na Universidade Federal de Santa Catarina (UFSC). 


\section{Resumo}

Este artigo trata da crítica de mídia a partir de uma matriz teórica mais ampla, voltada para uma apreciação crítica do papel e das funções de diferentes mídias, tendo como referência e horizonte uma prática comunicativa dirigida para o bem comum. Essa crítica tem como parâmetro a relação e o comprometimento da mídia com o interesse coletivo e a justiça social. Essa matriz teórica, conhecida como teoria crítica, cumpre importante papel, inclusive o de fomentar um bom trabalho de crítica de mídia enquanto atividade específica - crítica de produtos, programas e conteúdos. A herança da teoria crítica é retomada neste estudo por costuras e releituras, num movimento cíclico de referências que dialogam e se modificam. O percurso da reflexão se organiza em quatro tópicos: breve discussão sobre o que é a teoria crítica e suas duas importantes matrizes; crítica e deslocamento dessas matrizes; indícios de um terceiro momento (a retomada); e a influência da teoria crítica nos estudos da comunicação.

Palavras-chave

Teoria crítica, escola de Frankfurt, crítica de mídia, matrizes teóricas, estudos da comunicação.

\section{Abstract}

This article approaches media criticism considering a broader theoretical foundation, which is related to the critical appreciation of the roles and functions of different media keeping in the horizon a communicative practice concerned with the common good. The standard this criticism is the relationship and responsibility of the media with the common good and with social justice. Such theoretical framework, known as Critical Theory, plays an important role in promoting good critical work in the specifics of the activity - criticism over goods, programs and content. The tradition of the Critical Theory is revised in this study through approximations and revisiting of references in a cyclical movement that creates dialogue and transformation. Our argument is organized in four topics: a brief discussion on what is Critical Theory and its two most important frameworks; the critique and shift of such frameworks; signals of a third new moment (the revisiting); and the influence of the Critical Theory in Communication studies.

\section{Keywords}

Critical theory, Frankfurt school, media criticism, theoretical matrixes, Communication studies. 
Neste artigo não estarei tratando da crítica de mídia enquanto atividade específica - crítica de produtos, programas ou conteúdos -, mas de uma matriz teórica mais ampla, voltada para a apreciação crítica do papel e das funções cumpridas pelas diferentes mídias, tendo como referência e horizonte uma prática comunicativa dirigida para o bem comum. Essa crítica, portanto, não tem como parâmetro a questão da qualidade em estrito senso, mas a relação e o comprometimento da mídia com o interesse coletivo e com a justiça social. Essa matriz teórica é conhecida como teoria crítica, e cumpre importante papel inclusive para fomentar um bom trabalho de crítica de mídia.

Permitam-me iniciar esta reflexão a partir de um relato em primeira pessoa: a teoria crítica esteve presente em diferentes momentos de minha trajetória acadêmica, em cada um deles revestindo-se de diferentes leituras. Iniciei minha formação (graduação e mestrado) na década de 1970, quando a teoria crítica estava na ordem do dia. Vivíamos ainda os ecos de 1968; os protestos nos Estados Unidos contra a guerra do Vietnã se propagavam pelo mundo num apelo pela paz e contra toda forma de imperialismo; na América Latina, movimentos revolucionários, motivados pelo exemplo da Revolução Cubana, foram dizimados pela implantação de ditaduras em diferentes países.

O Brasil governado pelos militares viveu seu "milagre econômico" como um milagre para poucos (esperando o crescimento do "bolo"). Sob as benesses do governo, vem ao ar a Rede Globo de televisão. Data também dessa época a criação dos cursos de comunicação social (substituindo e incorporando os cursos de Jornalismo, Relações Públicas e Publicidade), e a palavra de ordem era a formação de profissionais críticos. Desenvolve-se a chamada escola latino-americana da comunicação, tendo como eixo central a crítica ao imperialismo cultural e a luta pela democratização da comunicação. A prática acadêmica e a militância política se misturavam. A base teórica que fundamentava essas reflexões e posicionamentos era teoria crítica; os conceitos de indústria cultural, alienação, massificação eram as referências para criticar tanto o imperialismo cultural latino-americano como as indústrias culturais nacionais. 
Nas décadas seguintes, 1980 e 1990, já como docente da Universidade Federal de Minas Gerais (UFMG), vivemos novos cenários e novas buscas conceituais. Foi a época das Diretas Já, da imensa comoção popular suscitada pela agonia e morte de Tancredo Neves, das grandes greves de diferentes categorias de trabalhadores, do surgimento de Luiz Inácio Lula da Silva e outras lideranças sindicais e da criação do Partido dos Trabalhadores (PT). Na sequência da Jovem Guarda e da Tropicália, surgem não só novas bandas de rock brasileiro, mas também cantores como Reginaldo Rossi e Almir Rogério, com músicas chamadas de "brega", porém alcançando estrondoso sucesso, como "Fuscão preto".

Como professora de teorias da comunicação, senti a insuficiência da teoria crítica para explicar tanto os movimentos da sociedade e os fenômenos de massa como o grande sucesso de músicas de qualidade duvidosa; apontar a massificação da audiência e considerar as pessoas como idiotas se revelava um caminho fácil e simplificador. Nesse momento, o pensamento dos teóricos de Frankfurt, considerado monolítico e elitista, começa a receber crítica de vários estudiosos; outras matrizes, capazes de escapar dos determinismos e avaliar melhor o papel do receptor, ocupam as reflexões acadêmicas. O debate em torno da pós-modernidade domina os anos 1980, sucedido por teorias que enfatizam o imaginário, a subjetividade e a particularidade dos sujeitos. O conceito de ideologia perde força e cede lugar aos debates sobre cultura e identidade.

Fazendo um grande salto, chegamos aos nossos dias e à situação vivida hoje pelo Brasil. Assistimos a polarização das eleições de 2014, o impeachment em 2015 e um cenário em que discursos de ódio e intolerância grassam nas redes sociais. A mídia hegemônica se mostrou vitoriosa em seu intento de vilanizar Lula, Dilma Rousseff e o PT e sustentar o golpe impetrado pelos políticos e pelas classes dominantes. O governo ilegítimo de Michel Temer consegue, em pouco mais de um ano, revogar direitos sociais, ameaçar conquistas e colocar o país à venda - e a sociedade reage mais com descrença do que com resistência. Isso sem falar no resto do mundo, na vitória de Donald Trump nos Estados Unidos, no fortalecimento dos movimentos de direita na Europa, nos conflitos que se 
perenizam na África e Oriente Médio e na fragilidade dos milhões de imigrantes em busca de acolhida.

Que referências teóricas se mostram adequadas para analisar esse cenário, levando em conta o papel da produção/circulação de informações e representações na constituição dos processos de formação de opiniões, nas dinâmicas e posicionamentos tomados pelos diferentes grupos na sociedade? A realidade pressiona as teorias existentes em busca de novas respostas, as bases teóricas estão voltadas para a singularidade dos sujeitos e as identidades múltiplas e a defesa do receptor crítico também se mostram limitadas. Surgem indícios de uma nova "virada" e da premência de um pensamento que leve em conta as dinâmicas estruturais e as relações de força na sociedade.

Esse momento estimula o resgate da herança da teoria crítica. Naturalmente, não se trata de um resgate puro e simples, mas de costuras e releituras, num movimento cíclico de referências que dialogam e se modificam.

Procurarei abordar essa retomada na reflexão que se segue em um percurso organizado em quatro tópicos: breve discussão sobre o que é a teoria crítica e suas duas importantes matrizes; crítica e deslocamento dessas matrizes; indícios de um terceiro momento (a retomada); a teoria crítica e os estudos da comunicação.

\section{A teoria crítica - duas matrizes}

A teoria crítica remete (e se identifica com) diretamente ao pensamento da escola de Frankfurt, sobretudo às reflexões de Theodor Adorno e Max Horkheimer. Devemos convir, no entanto, que ela é mais extensa do que essa escola, e compreende diferentes contribuições voltadas para a denúncia e crítica das relações de dominação predominantes na sociedade capitalista em suas diferentes fases.

Conforme J.-L. Laville (2015, p. 407, tradução minha), "a Teoria Crítica, preconizada por Marx desde 1843, tem por objeto clarificar as lutas e aspirações em andamento no mundo, a fim de preparar o advento de um projeto Emancipatório".

Nessa linha de entendimento, podemos dizer que a teoria crítica, mais do que uma teoria específica, é uma perspectiva paradigmática, um conjunto de 
parâmetros que orientam/possibilitam a construção de diferentes teorias. É uma perspectiva que ultrapassa um tratamento descritivo da realidade; ela não tem um estatuto metafísico, mas sócio-ontológico, nos diz Boltanski (1990). De forma sintética, entendemos que ela se caracteriza por três pontos:

a. apoia-se num pano de fundo estrutural (numa "gramática social"). É uma abordagem histórica e contextualista;

b. pressupõe a existência de relações sociais desiguais - de um projeto de dominação. Seu operador analítico é a noção de poder;

c. tem como horizonte uma perspectiva de emancipação - de justiça social.

Trata-se, portanto, de uma matriz teórica que orienta uma análise da sociedade em seus diferentes aspectos - e não especificamente nas práticas comunicacionais. No que tange à comunicação, direciona análises que buscam conjugar o tratamento de situações, práticas e produtos específicos, bem como o funcionamento da mídia de maneira geral, com visada mais ampla, que leva em conta os três aspectos apresentados anteriormente (a abordagem contextual, as relações de poder e o compromisso com a emancipação).

Vários autores e escolas podem se inscrever nessa rubrica de "teoria crítica". Dentre eles, duas grandes matrizes se destacam ${ }^{3}$ : como já assinalado, a escola de Frankfurt (1940-1950), radicada nos Estados Unidos; a sociologia crítica de Pierre Bourdieu na França (1960-1970)4.

Essas duas escolas foram referências teóricas fortes em meados do século passado (até por volta da década de 1980). Em sua crítica ao capitalismo, ambas têm em comum a superação do economicismo marxista; e promovem crítica à dominação capitalista com ênfase no papel da cultura, que seria aviltada pela ideologia e instrumentalizada para a manutenção da dominação.

3 Outra importante matriz (que, no entanto, não será tratada neste artigo) é o pensamento de Antonio Gramsci, que estimulou em grande medida o pensamento crítico latino-americano nos anos 1970. 
O pensamento da escola de Frankfurt é relativamente familiar aos estudiosos da comunicação, sobretudo a partir do conceito de indústria cultural, que enfatiza o processo de mercantilização da cultura, a alienação e a manipulação dos membros da sociedade, transformados em "massa". Para Adorno e Horkheimer (1990, p. 189-191),

As massas desmoralizadas pela vida sob a pressão do sistema e que se mostram civilizadas somente através dos comportamentos automáticos e forçados, [...] devem ser disciplinadas pelo espetáculo da vida inexorável e pela contenção exemplar das vítimas. A cultura sempre contribuiu para domar os instintos revolucionários bem como os costumes bárbaros. A cultura industrializada dá algo mais. Ela ensina e infunde a condição em que a vida desumana pode ser tolerada. [...]

$\mathrm{Na}$ indústria cultural o indivíduo é ilusório não só pela estandartização das técnicas de produção. Ele só é tolerado na medida em que sua identidade sem reservas com o universal permanece fora de contestação.

Essa perspectiva é reforçada por Marcuse (1967, p. 31-32, grifos do autor), que diz: "A produção e a distribuição em massa reivindicam o indivíduo inteiro; [...] os produtos doutrinam e manipulam: promovem uma falsa consciência que é imune à sua falsidade. [...] Surge assim um padrão de pensamento e comportamento unidimensionais", expressão acabada da castração dos indivíduos promovida pela sociedade capitalista avançada.

Na França, a escola crítica teve em Bourdieu sua figura de proa. A reflexão abrangente e vigorosa desse sociólogo, que abarca e incorpora várias tradições sociológicas ${ }^{5}$, recebeu também uma forte inspiração da escola de Frankfurt. Em sua extensa obra, ele teoriza o processo de "reprodução": a ideia de que os dominados participam e reproduzem as condições da própria dominação, vivendo uma violência simbólica (mecanismo que promove a despossessão de um agente social com a sua cumplicidade) e a incorporação inconsciente de comportamentos - o habitus. 
Bourdieu enxergava o senso comum (a doxa) como profundamente ideológico, mantendo iludido (imerso numa falsa consciência) o cidadão comum. Assim, apenas o sociólogo, por seus métodos científicos de afastamento crítico, teria condições de "desvelar" os mecanismos que atuam na dominação da sociedade.

\section{O surgimento das "segundas" escolas}

Por vários motivos, essas duas escolas foram bastante criticadas a partir dos anos 1980. Inicialmente, por seu determinismo, pela crença em uma dominação inexorável, marcada pela onipresença e onipotência do poder. O complemento natural dessa visão determinista era uma compreensão redutora dos agentes sociais, negando-Ihes qualquer capacidade crítica e de resistência, pela concepção de uma massa dominada. Também foram criticados pelo elitismo (escola de Frankfurt) e pela separação rígida entre ciência e senso comum, em razão da qual apenas o filósofo ou sociólogo poderiam alcançar alguma clarividência.

As críticas geraram reorientações tanto na Alemanha quanto na França.

A teoria crítica da escola de Frankfurt passou por mudanças ao longo da segunda e terceira gerações, com Jürgen Habermas e Axel Honnet. Habermas fez uma crítica da "razão instrumental" (crítica sistemática da razão pela primeira teoria crítica), reivindicando, em sua teoria do agir comunicativo, outro tipo de racionalidade. De acordo com o filósofo, Adorno e Horkheimer deixaram de considerar as experiências morais e os engajamentos normativos dos atores sociais. Assim, ele afirma "a credibilidade e racionalidade dos engajamentos normativos, [...] e busca na pragmática da comunicação os fundamentos de sua Teoria Crítica" (GENARD, 2015, p. 40, tradução minha). Negando a inexorabilidade do projeto de dominação, Habermas vê uma saída (e um processo de construção democrática) por meio das práticas discursivas e da troca de argumentação em processos deliberativos amplos.

Honnet, por sua vez, compartilhando a crítica de Habermas à primeira geração, desloca a ênfase deste último na expectativa de uma comunicação bem-sucedida com as experiências morais de luta pelo reconhecimento que 
afetam a construção identitária de grupos minoritários e/ou marginalizados. "A Teoria Crítica se vê a partir daí construída sob o horizonte do reconhecimento moral dos atores - enquanto sujeitos morais - e de seu reconhecimento social - enquanto membros ativos da sociedade" (GENARD, 2015, p. 40, tradução minha, grifos meus).

Já na França, a crítica a Bourdieu se deu pela sociologia pragmática da crítica. Nos anos 1980, Luc Boltanski, ex-discípulo de Bourdieu, promove uma ruptura com a sociologia do mestre na medida em que ela se atém à lógica estrutural que rege a dinâmica social, operando por intermédio da fragilidade e contribuição dos atores sociais -desprovidos de consciência crítica. Boltanski desenvolve uma antropologia do ator competente, provido de natureza moral e senso de justiça.

Ele discorda de Bourdieu tanto por supor a exterioridade (afastamento crítico) do sociólogo frente à sociedade (para Boltanski, o sociólogo está imerso na mesma trama social que os sujeitos comuns) quanto pela suposta incapacidade desses sujeitos. Em vez de uma separação, Boltanski aponta um continuísmo entre sujeitos sociais e sociólogos, ambos utilizando os mesmos métodos de leitura da realidade (vemos aí sua proximidade com a etnometodologia - na qual o sociólogo busca apreender e interpretar os métodos utilizados pelos sujeitos sociais para dar sentido e realizar suas ações no dia a dia).

Assim, tanto na Alemanha quanto na França, as matrizes frankfurtianas e bourdieusianas da teoria crítica se veem criticadas pela geração seguinte das respectivas escolas, em nome da experiência e intervenção dos sujeitos, de sua possível autonomia ética. Genard (2015, p. 44, tradução minha, grifos meus), numa leitura pertinente, observa que

A aproximação desses dois encaminhamentos, da Escola de Frankfurt primeiramente, de uma das tendências da sociologia francesa em seguida, permite perceber percursos e evoluções relativamente comparáveis quanto à passagem de uma teoria crítica de fundamento estruturalista para uma teoria crítica apoiando-se em fundamentos éticos e morais. Um apoio que se traduz principalmente pelo reconhecimento das competências morais 
dos atores, por levar a sério suas experiências éticas, pela adoção de uma epistemologia continuísta entre as competências cognitivas e morais dos atores e aquelas do sociólogo.

Nessa transição que caracteriza o surgimento das segundas escolas, Genard identifica um movimento da própria antropologia na maneira de apreender a relação entre ator social e valores. Para falar disso, ele retoma uma hipótese de Foucault sobre a configuração de um novo indivíduo na modernidade.

A hipótese de Foucault toma como ponto de partida as antinomias, apontadas por Kant, entre liberdade e determinismo, autonomia e heteronomia. Essas antinomias seriam, conforme Foucault, constitutivas da antropologia da segunda modernidade (a que se inaugura nos séculos XVII e XVIII), quando o indivíduo se torna um "duplo empírico-transcendental". Ou seja, esse indivíduo é aquele que se vê tensionado entre um e outro polo da antinomia, que vive sua existência empírica assombrado pelo desejo de transcendência.

Genard estende a hipótese foucaultiana do duplo e, elencando vários dualismos - natureza/cultura, espírito/corpo, valores/fatos -, sugere que os dualismos podem ser interpretados de duas maneiras: disjuntiva (isto ou aquilo) ou conjuntiva (isto e aquilo). Então, se a antinomia é de fato constitutiva de nossa modernidade (a existência de polos contraditórios), a maneira como ela se constrói pode variar ao longo do tempo: "Se durante o séc. XIX e grande parte do séc. XX prevaleceu a acentuação disjuntiva, foi em seguida, e atualmente, antes a acentuação conjuntiva que parece se impor" (GENARD, 2015, p. 52, tradução minha, grifos meus).

De igual forma, explorando a distinção entre disjunção e conjunção, Genard se refere ainda a um trabalho de Apel sobre o debate explicar-compreender (ou seja, sobre o trabalho do conhecimento), no qual o filósofo alemão identifica duas fases. A primeira delas é marcada por uma crítica ao positivismo e à sua tentativa de aplicar nas ciências da sociedade os mesmos métodos das ciências da natureza, crítica essa que reivindica a especificidade das ciências humanas, voltadas para a compreensão do sentido (Dilthey seria o maior expoente dessa fase). 
Na segunda delas, representada por Wittgenstein (e os jogos de linguagem), a disjunção cede lugar à conjunção. Explicar e compreender não são mais tratamentos excludentes: abordagens objetivantes e hermenêuticas deixam de se opor e se complementam. Causalidades e sentidos podem ser buscados. Aqui objetos hermeneuticamente distintos cedem lugar à pluralidade de olhares sobre os mesmos objetos.

Essas duas posturas - conjunção, disjunção - podem ser encontradas no âmbito da ciência (que tanto pode perguntar por que causas como por quais razões), mas também na vida cotidiana e de indivíduos ordinários. A antropologia da conjunção (que orienta uma epistemologia conjuntiva) explica esse movimento da teoria crítica, nos diz Genard, que passa de uma abordagem estruturalista para outra que leva em conta as experiências de vida, a natureza moral, as afetações e reações dos indivíduos.

A constatação do dualismo também estimula um novo olhar sobre os seres humanos, que deixam de ser vistos como sujeitos passivos, presos em engrenagens determinantes, para serem considerados como seres que agem, resistem, são afetados, assumem múltiplas identidades (conforme os diferentes registros ou quadros teóricos).

\section{Um terceiro momento?}

No entanto, os desdobramentos das teorias críticas não param por aí. As transformações e desafios trazidos pela realidade contemporânea impulsionaram, em nossos dias, uma nova reorientação, que incide agora sobre as "segundas" escolas, estimulando inclusive o resgate e releitura das primeiras.

Dois indicadores podem ser aqui evocados. Um deles, no âmbito acadêmico, é o questionamento crescente, por parte de vários autores, da ênfase nas questões do reconhecimento e identitária. As limitações e riscos apontados dizem respeito ao encobrimento das relações de classe e às dinâmicas estruturais, ao fomento dos fundamentalismos, ao abandono dos projetos globais em nome de particularismos e, em última instância, ao que seria uma concessão ao individualismo liberal privilegiando as satisfações individuais. 
Em síntese, o que essa crítica aponta é a tendência ou o risco de que o aprofundamento das críticas em eixos verticais (particularidades) estaria se fazendo em detrimento da compreensão dos eixos horizontais que unem/dividem a sociedade de classes (a dinâmica estrutural). Em última instância, as novas tendências estariam impulsionando lutas e defesas de interesses específicos e abandonando projetos coletivos.

Um segundo indicador vem do terreno das lutas e movimentos sociais. Boltanski, em Le nouvel espirt du capitalisme (Novo espírito do capitalismo, 1999), chamou a atenção para o refluxo da crítica - que fora muito intensa nos anos 1965-1975, e se viu reduzida ao silêncio nos anos seguintes (1985-1995). No entanto, naquele momento (final dos anos 1990), ele percebia indícios de uma reversão da tendência.

Em publicação mais recente (BOLTANSKI, 2015), ele avalia que essa reversão aconteceu. Nos primeiros anos do século XXI, movimentos críticos acontecem em vários âmbitos da sociedade - nas relações de trabalho, no seio das empresas, na reação aos cortes das políticas públicas. A mesma tendência se verifica no campo acadêmico, e vários autores - nos campos da filosofia e da sociologia - retomam a tradição da perspectiva crítica e promovem debates propondo seu resgate e atualização.

Não obstante, o sociólogo destaca um ponto crucial - a forte distinção entre os dois momentos (os anos 1965-1975 e a atualidade), que diz respeito ao efeito da crítica, ao seu poder e sua capacidade de atuar na realidade. "Parece-me que hoje, o aumento da presença da crítica não se faz acompanhar de um crescimento no mesmo grau de um poder da crítica, como se esta não tivesse mais pegada sobre a realidade" (BOLTANSKI, 2015, p. 190, tradução minha, grifos meus).

Sobre esse novo fenômeno, o autor levanta mais indagações do que respostas. Mas o caminho de sua reflexão aponta para a eficácia - e o poder dissuasivo - da dominação gestionária, das novas formas de governança. No cenário contemporâneo, as formas de resistência crítica e reflexiva encontram grande dificuldade para ultrapassar as representações que as instituições impõem 
da realidade econômica, social ou política, ao seu poder de impor quadros e referências de leitura das coisas do mundo ${ }^{6}$. Os dispositivos de governança atuais confundem nossa apreensão da realidade e desarmam a possibilidade de criticála. Esses dispositivos são determinados principalmente pela economia - que, conforme Frère (2015a, p. 27-28), substitui a história como instrumento principal de formulação de uma narrativa englobante.

Existem várias formas de dominação, nos diz Boltanski (2015): dominação pelo terror, dominação ideológica e, agora, dominação gestionária. Cada uma delas contém - e ao mesmo tempo desenvolve - formas próprias de se contrapor e esvaziar as críticas. E para cada uma delas se faz necessário adotar formas específicas de resistência e conquista de espaço.

Pensar sobre isso é um grande desafio reflexivo colocado para a sociologia e a ciência política, bem como para cada um(a) de nós enquanto cidadãs e cidadãos. Resta, contudo, indagar de que maneira essa discussão toca nosso domínio de estudo e pesquisa, que é o campo comunicacional.

\section{A influência da teoria crítica nos estudos comunicacionais}

Esse tema demanda reflexão mais aprofundada, que ultrapassa os objetivos deste texto, voltado de forma menos pretensiosa para o ressurgimento e a atualidade da teoria crítica. Finalizo com breves apontamentos, pistas para um tratamento posterior mais desenvolvido.

No campo das pesquisas em comunicação, a teoria crítica de matriz frankfurtiana, por meio do conceito de indústria cultural, nos estimulou a analisar e explicitar o comprometimento da mídia com interesses particulares e a natureza ideológica dos produtos midiáticos, bem como denunciar a manipulação das massas. A matriz bourdieusiana, de igual forma, chamou nossa atenção para a inserção estrutural dos meios de comunicação (propriedade dos meios) a serviço da reprodução das condições de dominação. 
A virada da teoria crítica em direção aos fundamentos éticos e morais que atuam e movem os indivíduos (com o surgimento das "segundas" escolas), a crença em sua capacidade de promover leituras críticas e reivindicar reconhecimento levaram os estudos comunicativos, numa linha mais normativa, a buscar e defender os processos deliberativos em diferentes instâncias da sociedade, escrutinar os argumentos que são acionados nos debates públicos e analisar e apoiar as lutas por reconhecimento. Também a desenvolver estudos de recepção, identificando resistências, processos de transformação e misturas.

Nesse terceiro momento, em que se busca uma retomada da primeira tradição, o eixo se inclina novamente para a dimensão mais ampla das relações sociais e o pano de fundo estrutural. Conforme Laville (2015 p. 419, tradução minha), é preciso "apoiar os esforços de emancipação sem esquecer as formas renovadas da dominação"; é preciso buscar a complementariedade entre as perspectivas que ressaltam a capacidade crítica dos atores e uma teoria que dê conta das relações de força em um nível macrossocial.

Vejamos o caso brasileiro, buscando refletir sobre os fundamentos teóricoconceituais mais adequados para analisar o papel da mídia na consumação do golpe de 2016 - o afastamento da presidenta Dilma sem comprovação de crime de responsabilidade, apoiado na convicção da culpa. Os meios de comunicação conseguiram formar uma ampla opinião pública favorável ao golpe e transformar a convicção em verdade, prescindindo de fatos comprobatórios. A grande mídia foi uníssona na versão que construiu, pautando a questão da corrupção e associando-a ao PT, acobertando acontecimentos comprometedores de políticos de outros partidos - sobretudo do Partido da Social Democracia Brasileira (PSDB) -, fazendo coberturas tendenciosas, distorcendo fatos, insuflando ódio e intolerância. Sobretudo isto: estimulando a polarização e a criação de dois campos, do bem e do mal.

Duas questões perturbadoras se colocam para nós, professores(as) de comunicação. A primeira delas é lembrar que os profissionais que hoje atuam nas mídias foram formados por nós. Terá faltado em nossas aulas uma certa dose de teoria crítica, buscando formar profissionais mais comprometidos - não 
com a verdade, que tem muitas faces, mas com a diversidade de enfoques, a multiplicidade de olhares - e aptos a se situar no embate dos diferentes interesses que atuam no jogo político, camuflados, na maior parte das vezes, de interesse público? Teremos falhado na construção de um olhar mais amplo sobre as práticas comunicativas, de forma a situar o fazer comunicativo, os produtos e os discursos produzidos e colocados em circulação em elos de uma dinâmica mais estendida que é a constituição da própria realidade social?

A segunda questão se refere à formação da opinião pública. Ouvindo os paneleiros, em 2016, ou assistindo ao imobilismo com o qual vivenciamos, em 2017, uma série de decisões políticas comprometedoras da soberania nacional e do bem-estar de grande parte da população, não teremos lembrado do velho Adorno, descrente da sagacidade das massas, denunciando não apenas a manipulação das informações, mas, por meio delas, aquela mais dolorosa, que é das consciências?

Decididamente, seria uma arrogância intelectual e um triste retrocesso falar da "imbecilidade das massas" ou, pior, na redução das pessoas ao estado de massificação. Significaria desconhecer inúmeros exemplos que atestam o poder de resistência, as barganhas e rusgas pelas quais homens e mulheres do povo enfrentam cotidianamente suas adversidades - conforme conceito de táticas, em Michel de Certeau (1996). Não podemos, no entanto, nos furtar a uma avaliação das diferentes condições da experiência.

Já se falou, em outros momentos, a propósito do trabalho da mídia, em "sequestro da experiência": a mídia estaria nos privando da experiência, condenando-nos a uma vida por procuração. Não concordo com a ideia - ao contrário, entendo que a mídia estende nossa experiência para muito além de nossa vivência imediata, traz referências distintas e alarga nosso horizonte de percepção. Portanto, enriquece ao trazer para nosso campo de apreensão elementos e questões que ultrapassam em muito nosso espaço de inserção física. Trata-se, no entanto, de experiências diferentes - e tanto nossa vivência imediata nos dá parâmetros para a absorção das representações fornecidas pela 
mídia como a mídia nos fornece referências outras para balizar/modificar nossos posicionamentos em nossa vida pessoal, cotidiana.

Existem domínios, porém, em que as esferas não se cruzam; alguns aspectos tratados/retratados pela mídia ultrapassam o alcance daquilo que podemos experienciar diretamente. Nesses casos, nossa experiência e absorção não têm outro parâmetro comparativo - e as referências (leituras) trazidas pela mídia se impõem com força de verdade.

Boltanski (2015) faz uma distinção pertinente entre "realidade" e "mundo". Realidade é usada no sentido de realidade construída socialmente por um conjunto de regras, rotinas, formas simbólicas e "testes" ou "provas" pelas quais temos que passar. Por mundo, o autor entende aquilo que acontece - o que remete à impossibilidade de conhecê-lo e controlá-lo completamente (BOLTANSKI, 2015, p. 192-197).

Ora, nossas experiências se enraízam tanto na realidade, como realidade construída, repousando sobre instituições, quanto no mundo. Mas enquanto as primeiras são facilmente reconhecíveis e exprimíveis, as segundas acedem muito mais dificilmente à reflexividade. É preciso, nos diz Boltanski (2015), confrontar realidade e mundo; esse confronto é necessário tanto para uma percepção mais apurada deste (daquilo que acontece) como para testar a evidência e atestar a legitimidade da realidade construída.

Ou seja, precisamos nos dar conta tanto da força como da complexidade das formas de experiência, da interferência e cruzamento de diferentes modos de vida no desenvolvimento das capacidades de crítica e ação dos indivíduos. A rede de causalidades e o leque possível de consequências não se resumem às fórmulas "influência da mídia" e "resistência à mídia". Esta nos possibilita experiências que se cruzam, complementam ou chocam com as experiências vividas de forma i-mediatas. Ela amplia o mundo vivido para além dos limites de nosso corpo e daquilo que podemos testar diretamente; nos torna, dessa maneira, mais potentes - e mais frágeis. Nesse contexto, não é adequado falar, então, de manipulação das consciências, de massificação dos indivíduos - mas de 
amplitude da realidade na qual, graças à mídia, nos vemos inseridos e do conjunto de referências (oriundas de nossa vivência, mas também de outras mídias) de que dispomos para lidar com ela. Daí a grande importância da pluralidade de informações; e daí também o perigo - e o poder - de uma mídia que hegemoniza dada concepção do real. Retomando a distinção trazida por Boltanski (2015), é preciso fazer confrontar "realidade" e "mundo", confrontar realidades distintas de maneira a dispor de um referencial mais amplo para promover a reflexividade de nossa experiência no mundo.

Susen (2015, p. 175, tradução minha), buscando estabelecer uma reconciliação entre Bourdieu e Boltanski, destaca a abordagem contextualista de ambos para nos lembrar: "a vida social na qual nos encontramos imersos constitui a 'gramática coexistencial', quer dizer, 'o pano de fundo relacional' de todas as nossas práticas experienciais". Nossa visão e nossas formas de ação no mundo estão relacionadas à sociedade e ao grupo social ao qual pertencemos, à posição que ocupamos na realidade que vivemos.

Para compreender essa dinâmica, uma boa teoria crítica - bem dosada, resgatando os elementos estruturais sem menosprezar a agência humana e a força da experiência - se faz essencial.

É essa a contribuição que a teoria crítica deve trazer para os estudos comunicacionais: a leitura e compreensão da inserção social dos sujeitos, do alcance de sua experiência, dos elementos e representações que essa inserção Ihes torna disponíveis, das forças sociais que agem sobre ele e do seu maior ou menor poder de resistência e reação nesse jogo de forças. Essa compreensão é indispensável para analisar seus posicionamentos, lugares de fala, leitura e opinião sobre a realidade. A teoria crítica não significa uma intervenção direta na realidade; ela é uma ferramenta de análise, um instrumento para produção de conhecimentos. Possibilita uma leitura crítica da realidade e uma crítica mais aguçada e horizontal da produção e do papel da mídia na construção dessa realidade. Esse conhecimento tem duplo alcance: incide, por um lado, na formação de bons profissionais para atuar na mídia, municiados com uma boa 
compreensão do alcance e da responsabilidade social de seu trabalho. Ao mesmo tempo, alimentando a crítica da mídia, a teoria crítica encontra outro canal de diálogo com a sociedade, incidindo no conhecimento comum, o conhecimento "das ruas", estimulando posicionamentos críticos e trazendo novas referências na interlocução entre os indivíduos "ordinários" (o homem comum) nas e com as diferentes mídias.

\section{Referências}

ADORNO, T., HORKHEIMER, M. A indústria cultural: o iluminismo como mistificação das massas. In: LIMA, L. C. (Org.). Teoria da cultura de massa. 3. ed. Rio de Janeiro: Paz e Terra, 1990. p. 159-204.

BOLTANSKI, L. Sociologie critique et sociologie de la critique. Politix: Revue des Sciences Sociales du Politique, Paris, n. 10-11, p. 124-134, 1990. Disponível em: <https://bit.ly/2KiIwLC>. Acesso em: 27 abr. 2018.

BOLTANSKI, L. ; CHIAPELLO, E. Le nouvel esprit du capitalisme. Paris: Gallimard, 1999.

Situation de la critique. In: FRÈRE, B. (Org.). Le tournant de la théorie critique. Paris: Desclée de Brouwer, 2015. p. 189-217.

CERTEAU, M. A invenção do cotidiano: artes de fazer. Petrópolis: Vozes, 1996.

FRÈRE, B. La relance de la critique. In: FRÈRE, B. (Org.). Le tournant de la théorie critique. Paris: Desclée de Brouwer, 2015a. p. 7-34.

FRÈRE, B. (Org.). Le tournant de la théorie critique. Paris: Desclée de Brouwer, 2015b. 
GENARD, J.-L. Sociologie critique, sociologie morale. In: FRÈRE, B. (Org.). Le tournant de la théorie critique. Paris: Desclée de Brouwer, 2015. p. 37-66.

LAVILLE, J.-L. La théorie critique: de l'impasse au renouveau: ecoles de Francfort, sociologies pragmatique et publique, épistémologies du Sud. In: FRÈRE, B. (Org.). Le tournant de la théorie critique. Paris: Desclée de Brouwer, 2015. p. 407-433.

MARCUSE, H. Ideologia da sociedade industrial. Rio de Janeiro: Zahar, 1967.

SUSEN, S. Une réconciliation entre Pierre Bourdieu et Luc Boltanski est-elle possible?: pour un dialogue entre la sociologie critique et la sociologie pragmatique de la critique. In: FRÈRE, B. (Org.). Le tournant de la théorie critique. Paris: Desclée de Brouwer, 2015. p. 151-186.

submetido em: 05 abr. 2018 | aprovado em: 14 maio 2018 